\title{
ABOLIÇÃO DA PENA DE MORTE E MUDANÇA INSTITUCIONAL Portugal, 1867
}

Maria João Vaz

Iscte - Instituto Universitário de Lisboa, Centro de Investigação e Estudos de Sociologia (CIES-Iscte), Lisboa, Portugal

João Estevens

Instituto Português de Relações Internacionais, Universidade Nova de Lisboa, Lisboa, Portugal

Resumo O artigo analisa a abolição de pena de morte para crimes civis em Portugal (1867), interpretando-a num quadro de mudança institucional. Argumenta-se que esta abolição teve origem numa efetiva penetração das ideias liberais transacionais na elite portuguesa e foi possibilitada pela acalmia no ambiente securitário nacional e transnacional. Tal permitiu que o estado se focasse no desenvolvimento da sociedade portuguesa e na sua modernização. Este progresso não poderia acontecer pela via socioeconómica, restando o progresso moral ou civilizacional como o caminho possível para alimentar a estratégia de progresso na segunda metade de Oitocentos.

Palavras-chave: pena de morte, movimento abolicionista, sistema penal, mudança institucional.

Abolition of the death penalty and institutional change. Portugal, 1867

Abstract This article analyses the abolition of the death penalty for civil crimes in Portugal (1867), which it interprets within a framework of institutional change. The authors argue that the origin of this abolition was an effective penetration of transactional liberal ideas among the Portuguese elite, and was made possible by the fact that the national and transnational security environment had calmed down, which in turn enabled the state to focus on the development and modernisation of Portuguese society. It was impossible for this progress to happen by socioeconomic means, which left moral or civilisational advances as the possible path to fuelling a strategy for progress in the second half of the $19^{\text {th }}$ century.

Keywords: death penalty, abolition movement, penal system, institutional change.

Abolition de la peine de mort et changement institutionneL. Portugal, 1867

Résumé : L'article analyse l'abolition de la peine de mort pour les crimes de droit commun au Portugal (1867) et l'interprète dans un cadre de changement institutionnel. Il soutient que cette abolition est le fruit d'une pénétration effective des idées libérales transnationales au sein de l'élite portugaise et qu'elle a été rendue possible par l'accalmie dans l'environnement sécuritaire national et transnational, ayant permis à l'État de se concentrer sur le développement de la société portugaise et sur sa modernisation. Ce progrès n'aurait pas pu s'opérer par la voie socioéconomique, il restait donc le progrès moral ou civilisationnel comme chemin possible pour nourrir la stratégie de progrès de la seconde moitié du XIXe siècle.

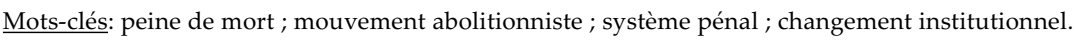

Abolición de la pena de muerte y cambio institucional. Portugal, 1867

Resumen El artículo analiza la abolición de la pena de muerte para crímenes civiles en Portugal (1867), interpretándola en un marco de cambio institucional. Se argumenta que esta abolición tuvo origen en una penetración efectiva de las ideas liberales transnacionales en la elite portuguesa y fue posible por la calma en el ambiente de seguridad nacional y transnacional. Tal contexto permitió que el Estado se enfocara en el desarrollo de la sociedad portuguesa y en su modernización. Este progreso no podría suceder por la vía socioeconómica, restando el progreso moral o civilizacional como el camino posible para alimentar la estrategia de progreso en la segunda mitad de mil ochocientos.

Palabras-clave: pena de muerte, movimiento abolicionista, sistema penal, mudanza institucional. 


\section{Introdução}

Este artigo analisa os fatores que originaram a transformação institucional do regime penal português, com a abolição da pena de morte em 1867, bem como a conjuntura que potenciou esta mudança institucional. Considerando que é possível percecionar o direito enquanto instituição (La Torre, 2010) podemos analisar a abolição da pena de morte segundo uma abordagem centrada na mudança institucional (Garland, 2010), apresentando-se como pertinente o estudo do caso português, um dos primeiros países a abolir do seu ordenamento jurídico-penal, e de forma definitiva, a pena de morte para crimes civis. O caráter percussor português justifica uma compreensão detalhada dos determinantes da tomada de decisão, pois devemos ter presente que o movimento abolicionista global só se torna efetivo quase um século depois. No início da década de 1970, eram pouco mais de uma dezena os países que tinham abolido (sem restrições) a pena de morte dos seus ordenamentos jurídico-penais (Anckar, 2004).

A discussão em torno da aplicação da pena de morte como instrumento para punir determinados crimes mantém-se atual, sobretudo nos EUA (Garland, 2010; Lyon, 2014) e nos continentes africano e asiático (Sarat e Boulanger, 2005; Johnson e Zimring, 2009; Hood e Deva, 2013; Karimunda, 2014; Novak, 2014), onde vários estados mantêm esta penalidade. Contudo, considerando o novo contexto global, em alguns estados identificam-se novas ameaças e, consequentemente iniciam-se novos processos de securitização, por vezes pressionando o direito penal a estender-se a novas áreas ou a endurecer as penas previstas (Costa, 2010). No contexto europeu, a reintrodução da pena de morte apresenta dificuldades várias, desde logo um bloqueio institucional por parte da União Europeia (UE), na medida em que os países pertencentes a esta são signatários do Protocolo 13 da Convenção Europeia dos Direitos do Homem, em vigor desde 2003, o qual evidencia a convicção de que o direito à vida é um valor fundamental das sociedades democráticas e a abolição da pena de morte acontece sem reservas. Este papel dissuasor esteve na génese da abolição da pena de morte na Turquia quando o país possuía pretensões de adesão à UE (Özbudun, 2007: 186). Com o afastamento entre Turquia e UE, o presidente turco Erdogan já tornou pública a possibilidade da reintrodução da pena de morte no ordenamento jurídico-penal turco. Também no seio da UE a questão não pode ser considerada como totalmente encerrada. Em 2015, o primeiro-ministro da Hungria, Viktor Orban, aventou a possibilidade da reintrodução da pena de morte no país, entendendo que tal poderia constituir um mecanismo de proteção dos cidadãos húngaros face a novas ameaças à ordem e segurança internas que relacionava com os elevados níveis de imigração (Bozóki e Hegedus, 2018: 1179).

O interesse em analisar o movimento abolicionista português reside em três dimensões: (a) Portugal integrou um primeiro grupo de países que aboliram a pena de morte, do qual não faziam parte as principais potências europeias, num contexto onde as três principais condições comummente apresentadas para a sua abolição desenvolvimento económico, democratização e expansão dos direitos humanos (Johnson, 2012) - não estavam verificadas; (b) o seu caráter irreversível e sem retrocessos formais, pese embora existissem, posteriormente, contextos que poderiam ter 
potenciado a reintrodução da pena de morte, como o Regicídio (1908), a forte conflitualidade política e social durante a I República ou o período de ditadura de Salazar; (c) a substituição da pena de morte pela prisão celular perpétua aconteceu num contexto em que a rede de infraestruturas penitenciárias era inexistente e em que o estado português não tinha os meios financeiros indispensáveis para proceder à construção dos estabelecimentos prisionais necessários (Vaz, 1998: 54; Marques, 2005: 106).

Considerando que as instituições do sistema penal, no qual se inclui o regime penal, são influenciadas pelo conjunto de ideias defendidas e pelos interesses de algumas elites (Lacey, 2014: 504-517), propõe-se aqui uma análise da mudança institucional assente em duas dimensões: (1) o impacto das ideias e, (2) o impacto dos interesses específicos provenientes do contexto. A circulação transnacional de ideias potenciou o contacto com diferentes modelos organizacionais e com novas formas de conceber os regimes penais, valorizando-se, nas práticas punitivas, determinados princípios e valores ao invés de outros. Todavia, estas ideias eram partilhadas internacionalmente, não sendo específicas da realidade portuguesa, podendo ter sido mais ou menos efetivadas em função dos interesses dos principais atores envolvidos e do contexto nacional e internacional existente à época. Uma última consideração metodológica para justificar a abordagem compreensiva realizada: 0 artigo assenta numa combinação de fontes secundárias, complementadas com fontes primárias, como a legislação, as atas dos debates parlamentares, os relatórios e reflexões concretizadas na época, procurando, assim, reconstruir e mapear o processo que culminou com a abolição da pena de morte.

\section{Mudança institucional}

As dinâmicas sociais, económicas e políticas das sociedades afetam os modelos institucionais existentes (Rueschemeyer, 2009: 210). Embora a origem histórica do conceito de instituição date do século XVIII, o desenvolvimento das análises institucionais é mais recente, surgindo associado à economia e expandindo-se nas últimas décadas para outras ciências sociais, como a sociologia e a ciência política, não existindo, contudo, uma definição e operacionalização unânime do conceito (Hodgson, 2006: 1). Aqui adota-se uma definição minimalista, assente na produção de um conjunto de normas, tanto formais como informais, que regulam e estruturam comportamentos numa determinada área (Steinmo, 2008: 123; Rueschemeyer, 2009: 210). A partir desta conceção é possível analisar as origens, as mudanças, as continuidades ou ruturas, bem como a influência das instituições em diferentes domínios societais (North, 1990; Thelen, 2003).

Nos últimos anos, têm-se desenvolvido duas áreas fundamentais no âmbito da análise institucional: o estudo dos mecanismos responsáveis pela mudança institucional e a avaliação do papel das ideias nas transformações políticas e históricas. A mudança institucional tem um papel crítico na (re)estruturação das relações de poder, embora apresente dificuldades várias, desde logo porque a produção de um novo quadro normativo pode promover mudanças institucionais paralelas, sendo necessário gerir expetativas e conceder um período de tempo para que os 
atores se adaptem a um novo enquadramento. As transformações institucionais podem ter origem em fatores endógenos ou exógenos (Steinmo, 2008).

É na interpretação da mudança que o papel das ideias pode ser fundamental, ao invés de se colocar a ênfase somente nos interesses associados aos diferentes atores envolvidos no processo de mudança institucional. A identificação de conjunturas críticas é fundamental para entender os avanços ou inovações institucionais que possam ter ocorrido (Moore, 2010 [1966]; Krasner, 1984; Collier e Collier, 1991; Thelen, 1999), tornando-se um elemento indispensável aos modelos de mapeamento de processos (Pierson, 2000; Mahoney, 2000), embora possam existir continuidades em supostas fases de rutura e mudanças em supostas fases de estabilidade das instituições (Thelen, 2003). Assim, a importância das conjunturas críticas parece ser a mais relevante para o estudo das transformações institucionais, por oposição a um estudo que se centre na origem das instituições (Rueschemeyer, 2009: 223-224).

Portugal foi um dos primeiros estados a romper com a instituição da pena de morte para crimes civis, tendo-o feito de forma definitiva pelo artigo $1 .^{\circ}$ da Carta de Lei de 1 de julho de 1867, pela qual D. Luís I sancionou o decreto das Cortes Gerais, de 26 de junho do mesmo ano. Este diploma legal determinava uma Reforma Penal e das Prisões que, além da abolição da pena de morte para crimes civis, colocava a prisão celular no centro do novo ordenamento penal, definindo as condições para o desenvolvimento do novo sistema penitenciário. Apenas um dia depois, a 2 de julho, foi promulgada a Carta de Lei que criava os corpos de Polícia Civil, em Lisboa e no Porto.

\section{Estado, controlo social e sistema penal}

As instituições do sistema penal tendem a refletir a cultura política e os valores sociais predominantes, estando as suas transformações igualmente associadas à evolução do próprio estado. Nesse sentido, o século XIX ficou marcado pela afirmação de novas conceções sobre o sistema penal (Foucault, 2013 [1975]; Emsley, 2007; Spierenburg, 2008).

As reformas no direito penal, sob influência dos filósofos iluministas, tenderam a refletir não só um novo direito de punir, mas também uma nova economia política da punição, com o poder de punir mais e melhor distribuído entre diferentes instituições, tornando-o mais regular, eficaz e rigoroso nos efeitos pretendidos. A afirmação da igualdade de todos perante a lei pressionou igualmente a redefinição das práticas punitivas (Spierenburg, 2011:36). O direito de punir passou de um poder pessoal do soberano, sujeito às suas vontades, para uma prerrogativa da sociedade, no sentido de se poder defender, existindo uma limitação social do poder do castigo. Se, por um lado, a nova legislação criminal tendeu a ficar marcada por uma codificação mais clara e maior proporcionalidade das penas, menor crueldade e arbitrariedade na sua aplicação, por outro lado, também ficou marcada pelo desenvolvimento de mecanismos de coerção mais rigorosos, de modo a efetivar o necessário controlo social (Hespanha, 2012). 
Não obstante as múltiplas variações do padrão weberiano de apropriação estatal do uso legítimo da violência, a concentração do direito de punir no estado subjugou a sua utilização ao interesse público, por oposição à dispersão entre diferentes atores públicos e privados que, anteriormente, poderiam executar o exercício do poder punitivo (Hespanha, 2012; Churchill, 2014). O desenvolvimento do direito penal contribuiu grandemente para esta transformação, apresentando-se, simultaneamente, como uma construção orientada para o combate ao crime e para a salvaguarda dos direitos fundamentais dos cidadãos. Nesse sentido, a condenação à morte depois de um ato processual mais não seria do que um homicídio levado a cabo pelo estado, que não deve utilizar recursos similares aos indivíduos, na medida em que detém o monopólio da violência legítima, esperando-se uma ação assente em premissas de racionalidade e responsabilidade em prol da defesa dos seus interesses enquanto estado, mas também da sua população (Bobbio, 2004 [1992]: 74).

Numa sociedade da ordem onde o estado passou a assumir a gestão da vida dos cidadãos, tornou-se mais difícil a aplicação da pena de morte, somente aceitável em casos com alguma excecionalidade, em que se assumisse a monstruosidade do ato criminal e a impossibilidade de regeneração do criminoso, transformando-o numa ameaça permanente para a sociedade. $O$ contexto liberal potenciou, assim, um novo enquadramento para o estado, que vincava a separação entre as esferas económica e política, bem como entre público e privado, assistindo-se a um redesenhar do sistema de distribuição de poder, com uma entidade, designadamente o estado, a exercer o monopólio do poder sobre uma determinada comunidade, que habita um determinado território, existindo um poder único e exclusivo sobre uma sociedade civil (Hoffding, 1912). O constitucionalismo liberal viria reforçar a nova era da justiça penal e introduzir novos modelos de controlo social formal e disciplina informal (Cohen, 1985; Garland, 2001).

Por outro lado, a alteração dos instrumentos punitivos foi em parte influenciada pela transformação das práticas ilegais, motivada pelo desenvolvimento do capitalismo industrial e uma maior valorização jurídica e moral das relações de propriedade, bem como pelo crescimento demográfico e das cidades, o que implicou a criação de novos métodos de vigilância e controlo da população e a evolução nas técnicas de identificação e captura do criminoso (Foucault, 2013 [1975]: 90-98).

Poder-se-á percecionar o sistema penal como um conjunto de instituições judiciais, policiais e prisionais subordinadas à lei penal. Historicamente, a tradição jurídica evita ruturas substantivas nos regimes penais, o que não invalida que novas instituições e novas configurações institucionais tenham surgido ao longo do século XIX, onde o crime continuava a ser um tema central da sociedade e da vida política, na medida em que era percecionado como uma ameaça à estabilidade social, necessitando, assim, de ser regulado e controlado (Vaz, 1998; Garland, 2001). A sua eliminação era considerada como essencial de modo a garantir a segurança pública e demonstrar um sinal de progresso da sociedade, evidenciando a superioridade das sociedades que o conseguissem alcançar (Spierenburg, 2008), devendo o desenvolvimento do estado e das sociedades acontecer através de um processo civilizador (Elias, 1990 [1939]). 
Na segunda metade do século XIX, num contexto de poucas ameaças externas ao estado português, os principais desafios à segurança aconteciam a nível interno, sendo o crime percecionado como um elemento central da ameaça à estabilidade nacional, surgindo a necessidade de garantir a manutenção da ordem e a segurança pública junto da população no interior do território (Vaz, 2014: 14-15). No caso português, a concentração de poder aconteceu no estado central, contudo este teve dificuldade em assegurar a sua presença na generalidade do território, o que trouxe novos desafios à aplicação dos mecanismos de coerção e controlo do território e das respetivas populações, justificando-se, assim, os relatos de falta de segurança em algumas zonas (Cerezales, 2011: 63-77). Por outro lado, a crescente afluência de pessoas às cidades e o seu consequente crescimento, proporcionou que, na época, o ambiente urbano fosse percecionado como potenciador da insegurança e do crime, suscitando exigências de uma maior vigilância sobre a população, de modo a garantir a ordem e a segurança de pessoas e bens (Vaz, 1998).

No início da segunda metade de Oitocentos, o sistema policial português assentava ainda na ação de autoridades tradicionais e de forças policiais militarizadas para os maiores espaços urbanos, e do exército para fazer o policiamento no resto do território, datando a criação da Polícia Civil do ano de 1867, data que materializa a criação de uma estrutura de policial não militarizada, à semelhança do modelo existente noutros países europeus (Gonçalves, 2014: 14). Os principais modelos de controlo social e ordenamentos jurídico-penais de referência em Portugal pareciam ter origem em Inglaterra e França, países que mantinham a pena capital (Marques, 2005: 97), ficando o século XIX marcado pela criação de várias estruturas policiais. A transformação do sistema policial português foi enquadrada pelas crescentes preocupações com a segurança pública, acontecendo a sua evolução à luz da realidade europeia, onde se desenvolveram estruturas similares: hierarquicamente estruturadas, burocraticamente controladas e com o objetivo de garantir a ordem e a segurança públicas (Perrot, 1980; Garland, 2001; Emsley, 2007).

As transformações no estado, no controlo social e no sistema penal contribuíram para o surgimento de novas ideias e narrativas dentro do movimento abolicionista, fruto de: (a) uma crescente diminuição das diferenças de poder entre grupos sociais, com um processo gradual de pluralização e periferização do poder a outras camadas sociais; (b) descoberta de novas formas de o estado exercer o seu poder punitivo sobre as populações de modo garantir o controlo social; (c) desenvolvimento de um poder judicial autónomo e em expansão, que se regia pelo princípio da legalidade.

\section{Circulação transnacional de ideias}

No século XIX, o desenvolvimento de uma rede de transportes e comunicações de alcance transnacional simplificou o acesso à informação sobre os instrumentos punitivos e os modelos de controlo social existentes em outros países. O processo de aproximação espacial permitiu intensificar a circulação de ideias e o contacto com pessoas e publicações com origem noutros contextos sociais, facilitando formas de 
correspondência e a participação em congressos internacionais, como os que se realizaram sobre questões do direito penal, das prisões e da criminalidade (Marques, 2013: 56), acontecendo esta circulação não só em movimentos centro-periferia, mas também periferia-periferia (Isabella e Zanou, 2015).

As ideias defendidas por Beccaria (1998 [1764]) na obra Dos Delitos e das Penas iriam décadas mais tarde modelar as reflexões sobre o crime e a justiça penal em toda a Europa, tal como as ideias de Jeremy Bentham, também ele partidário da não utilidade da aplicação da pena de morte. Em sentido contrário, John Stuart Mill manteve-se favorável à aplicação da pena morte para crimes de homicídio, em particular no caso britânico, que possuía, na sua opinião e ao contrário de alguns países da Europa continental, tribunais e um procedimento criminal capazes de garantir a necessária isenção e confiança, apontando o erro judiciário como o principal obstáculo à aplicação da pena de morte, na medida em que apresentava um caráter irreversível. A abolição da pena de morte, ou a sua aplicação a um número mais reduzido de crimes, colocou a pena de prisão celular no centro da punição. A prisão apresentou-se como um mecanismo do poder disciplinar normalizador característico do desenvolvimento capitalista (Foucault, 2013 [1975]: 357-358), mas também como o espaço de correção do criminoso, podendo ser, na opinião de muitos liberais, mais cruel do que a aplicação da pena de morte, tal como defendeu Mill, em abril de 1868, no discurso na Câmara dos Comuns britânica (Mill, 2001 [1861-1868]).

Com o liberalismo, a punição foi gradualmente perdendo a dimensão ritualística e ganhando um caráter processual e administrativo (Foucault, 2013 [1975]; Garland, 1990). Para esta mudança foi essencial a supressão do espetáculo público associado à punição e a diminuição do recurso ao castigo físico, com consequências no tipo de penas consagradas nos códigos penais nacionais, em particular um afastamento em relação à aplicação da pena de morte, substituída pelo encarceramento (Ignatieff, 1981: 159). Outra das principais ideias trazidas pelo liberalismo, incorporada na teoria da finalidade das penas, foi a dimensão preventiva associada às penas, deixando de se centrar somente na escola clássica retributiva, que se funda a partir de Kant (1998 [1785]) e Hegel (2005 [1821]), passando a considerar os efeitos de prevenção, como foi teorizado pelo utilitarismo penal, a antropologia criminal, o positivismo sociológico ou os estudos correcionalistas (Romão, 2015: 343).

Em Portugal, no período prévio à abolição da pena de morte, foram várias as referências, nos debates parlamentares, a Beaumont, Beccaria, Bentham, Filangieri, Mably, Mittermeier e Tocqueville (Marques, 2005: 97), confirmando-se que houve uma efetiva penetração das suas ideias sobre o sistema penal no parlamento português. Ainda antes, logo após a Revolução Liberal de 1820, Bentham ofereceu um modelo de código penal aos governantes portugueses, mantendo-se em contacto com as elites liberais portuguesas nesse período (Fuller, 2000). Também os escritos de diferentes pensadores sobre a pena de morte parecem ter chegado à elite portuguesa, fossem aqueles que em favor dela escreveram, como Montesquieu, Rousseau, Mably, Filangieri, Kant, Beck, Rotteck, Romagnosi, Portalis, entre outros, ou contra, como Heving, Thomasius, Michaelis, Beccaria, Pastoret, Bentham, Carmignani, Lamartine, Lucas, Sellon, Livingstone, Ellero, entre outros (Jordão, 
1861: 58). Jordão (1853), ao analisar o Código Penal português de 1852, mencionava os nomes de Rousseau, Beccaria, Voltaire, Servan, Mably e Brissot para defender a necessidade de evitar abusos e fixar os necessários limites ao direito de punir. Também Victor Hugo, um acérrimo abolicionista por considerar a pena de morte uma prática que não se coadunava com uma civilização do século XIX, refletiu sobre a pena de morte na sua produção literária, em Os Últimos Dias de Um Condenado (1829), A Pena de Morte (1854) ou Os Miseráveis (1862), tal como o fizeram outros abolicionistas como Lucas (1831), Ducpétiaux (1827), Guizot (1838), Caicedo (1864) ou Mittermaier (1865), obras que influenciaram a elite abolicionista portuguesa, essencialmente composta por professores de direito, jurisconsultos e escritores (Fernandes, 1971: 12 e 19).

O contacto direto com realizações no estrangeiro permitiu igualmente a apropriação de ideias. Nesse sentido, Ayres Gouveia realizou visitas a penitenciárias em Inglaterra, Escócia, França, Suíça, Bélgica, Holanda, Prússia, Áustria e Espanha, para, em 1860, propor reformas nas prisões em Portugal. A incorporação da centralidade da prisão no sistema penal português, bem como a sua função de recuperação do indivíduo delinquente para a vida em sociedade evidenciam a influência das ideias transnacionais no funcionamento do sistema prisional português (Gouveia, 1860: 99), pese emboras as várias dificuldades no seu funcionamento, como a sobrelotação e a ausência de condições de segurança e higiene (Vaz, 2003: 14).

O debate sobre a pena de morte que ocorre em Portugal também foi comentado no estrageiro, como o fez Mittermaier (1865), ou como consta do relatório apresentado no parlamento britânico, The Capital Punishment Commission, em 1866, primeiro acerca da abolição de facto e, posteriormente, sobre a abolição formal da pena de morte em Portugal. Neste relatório foi apresentada uma ampla análise sobre a pena de morte nos vários países europeus, designadamente sobre os crimes que eram punidos com a pena capital e aqueles que tinham deixado de o ser, as possibilidades de comutação da pena e a frequência com que acontecia, a intervenção do poder real, as penas alternativas existentes nos ordenamentos jurídico-penais nacionais e o tipo de execução (pública ou privada), permitindo, assim, a comparação da realidade britânica com a dos restantes países europeus. A correspondência recebida de Portugal foi assinada por Gaspar Pereira da Silva, então ministro dos Negócios Eclesiásticos e Justiça, que não só respondeu às questões supramencionadas como também enviou o projeto de lei número $6 \mathrm{~K}$, respeitante à abolição da pena de morte para crimes civis. Já após a abolição da pena de morte em Portugal, assinalaram-se ecos transnacionais, destacando-se a manifestação de Victor Hugo, em resposta à carta de Brito Aranha, datada de 15 de julho, e ainda antes, a 2 de julho, em carta enviada ao então redator do Diário de Notícias, Eduardo Coelho, não só elogiando a posição portuguesa, como colocando Portugal como um exemplo a seguir por toda a Europa (Carneiro, 1984). O jornal francês Courrier de l'Europe, na edição de 10 de agosto de 1867, classificava a abolição da pena de morte como um acontecimento marcante para a história da civilização (Fernandes, 1971: 27). Lucas (1869) escreveria sobre o acontecimento no relatório que apresentou na Academie des Sciences Morales et Politiques, tal como o fariam Eyttel (1868), Crouzel (1884), 
Bujon (1886) ou Olivecrona (1893). Internamente, o debate sobre a pena de morte continuaria ativo nos anos seguintes na imprensa e na opinião pública (Pedroso, 1874: 7)

Assim, a circulação transnacional de ideias é fundamental para se compreenderem as reformas penais que foram sendo implementadas em Portugal. A um contacto direto proveniente das viagens ou do exílio de elementos da elite política portuguesa, e um contacto indireto através da leitura de obras e jornais, da correspondência com pensadores no estrangeiro, pode-se adicionar a participação de membros da elite portuguesa em encontros internacionais sobre matérias de interesse para o sistema penal, ou seja, em comunidades epistémicas. Percecionando o binómio crime-punição como uma construção social historicamente determinada, é possível compreender que a afirmação e inclusão de uma nova visão punitiva na praxis do estado foi uma manifestação decorrente do poder existente, devendo a abolição da pena de morte em Portugal ser entendida à luz deste novo ideário liberal, mas também do desenvolvimento do estado liberal, ambos fundamentais para a institucionalização do sistema penal e das práticas de controlo social.

\section{Contexto político e socioeconómico}

Em Portugal, houve uma acalmia do ambiente político e social a partir 1851, concretizando-se a extinção das principais instituições que ainda ligavam o país ao Antigo Regime, a reconciliação entre as grandes famílias políticas responsáveis por grande parte das tensões vividas na primeira metade do século e um distanciamento face às convulsões populares e guerras civis das décadas de 1830 e 1840. Atenuam-se as maiores dissidências políticas, não existindo substanciais problemas de unidade, identidade e estabilidade do estado português (Reis, 1993: 250-252). Contudo, desta acalmia não resultou uma substancial diminuição dos níveis médios de criminalidade em Portugal, na segunda metade do século XIX (Vaz, 1998: 131-160), que continuava a ser considerada como uma das principais ameaças à segurança $\mathrm{e}$ tranquilidade públicas. A segurança pública e o controlo social passaram a ser encarados como elementos fundamentais para a afirmação do estado liberal, tendo o aparelho de estado reforçado as suas instituições policiais e judiciais.

Renova-se o contexto político-partidário, que passa a funcionar segundo um sistema de bipartidarismo, com os dois principais partidos a assumirem, de forma alternada, o poder. A ideia de progresso seria central para designar a modernidade desejada (Justino, 2016: 454), sendo este período caracterizado pelo reforço da capacidade burocrática e administrativa do estado, bem como do seu poder disciplinar. De forma tardia e lenta, a estratégia passava por seguir o contexto europeu, assentando na construção de estradas e caminhos-de-ferro, no desenvolvimento do comércio internacional e dos níveis de industrialização, bem como na garantia de segurança e melhoramento das condições de vida da população. No entanto, o país não apresentava recursos internos para alimentar esta estratégia, sendo necessário recorrer a empréstimos externos, levando a uma grande acumulação de dívida pública (Fernandes, 2005: 410). 
No relacionamento com o exterior, a história das relações internacionais portuguesas parece retratar a segunda metade do século XIX como um período de paz e relativa tranquilidade, estando as principais crises diplomáticas e com potencial de conflito associadas a uma dimensão colonial. A ausência de um conflito iminente com o exterior e a relativa estabilidade interna reforçaram as condições necessárias para que as elites políticas nacionais se centrassem maioritariamente em questões internas.

Portugal não conseguiu acompanhar a evolução económica que se fazia sentir na Europa, na segunda metade do século XIX, mesmo em relação aos países do sul da Europa, como Espanha e Grécia que, em 1870, apresentavam um PIB per capita próximo do português, mas cujas taxas de crescimento foram aproximadamente o dobro da portuguesa, até ao início da I Guerra Mundial (Broadberry e Klein, 2012: 99). Este atraso poderá, em parte, ser explicado com a desagregação do espaço imperial português do início do século XIX, implicando uma reorganização e reconversão do sistema comercial e do aparelho produtivo, num contexto de profunda transformação proveniente da divisão internacional do trabalho (Pedreira, 1998: 456). Com a perda do mercado colonial brasileiro aumentou a necessidade de diversificação de mercados externos, na medida em que o país vira desaparecer a sua posição de intermediário no comércio externo brasileiro, perdendo um mercado protegido para o escoamento dos produtos nacionais (Pereira, 2001: 66). Contudo, os progressos registados na economia portuguesa, na segunda metade do século XIX, não foram suficientes para que o país conseguisse superar o diferencial de crescimento económico acumulado durante décadas.

O perfil sociodemográfico da população portuguesa também parece ser relevante, na medida em que permite aferir o grau de desenvolvimento do país. Diferentes níveis de desenvolvimento dão origem a diferentes vias para promover o crescimento económico (Lains, 1995: 21), tendo Portugal apresentado, entre 1850 e 1910, uma das taxas de analfabetismo mais elevadas da Europa, sendo uma das que menos diminuiu nesse período, residindo a explicação nos reduzidos problemas de unidade, identidade e estabilidade do estado português, algo que teria constituído um incentivo ao desenvolvimento do sistema educativo, enquanto elemento aglutinador da identidade nacional (Reis, 1993: 250-252).

\section{Movimento abolicionista em Portugal}

A imagem da repressão extrema do Antigo Regime é, por vezes, exagerada, em particular quando se compara com a primeira metade do século XIX, desde logo porque não existe uma clara diminuição do número de execuções (Hespanha, 1989: 517). A arbitrariedade no estabelecimento das penas podia levar, em muitos casos, a uma cultura misericordiosa, com os juízes a fazerem uma interpretação mais benevolente de modo a aplicar uma pena menos severa, ou o rei a intervir no sentido da comutação da pena. Ainda assim, as penas pareciam ser marcadas por grande crueldade e as ordenações penais assentavam em critérios mais arbitrários, desiguais e casuísticos. O constitucionalismo liberal veio romper com este enquadramento penal, pese 
embora se assinalem algumas iniciativas anteriores. Em 1789, o projeto de Código Criminal de Pascoal José de Mello Freire visava uma reformulação do enquadramento das matérias de direito penal e uma maior humanização das penas, não eliminando, no entanto, a pena de morte (Freire, 1823). Mais tarde, em 1803, uma nova reflexão sobre crime e punição, da autoria de Joaquim José Caetano Pereira de Sousa, voltava a incorporar os novos valores liberais e, em 1815, António Ribeiro dos Santos publicava um ensaio criminalístico que advogava a abolição da pena de morte, exceto em situação de ameaça ao estado (Santos, 1815). Também Forjaz de Sampaio, nomeado em 1821, pelas Cortes Constituintes, para a comissão encarregada de projetar os códigos de processo criminal e de delitos e penas, publica, em 1823, um texto onde, seguindo as ideias de Beccaria, advogava a não necessidade da pena de morte.

Com a primeira experiência liberal, em 1820, inicia-se o processo de reestruturação do estado, materializando-se a rutura formal com as ordenações provenientes do Antigo Regime logo na Constituição de 1822. Aqui, o artigo 11. elimina algumas penas consideradas como demasiado cruéis, atribuindo uma maior humanização jurídica ao entendimento das penas. Elimina-se a desigualdade das penas, no artigo 9. ${ }^{\circ}$, inserindo-se os princípios da necessidade e da proporcionalidade

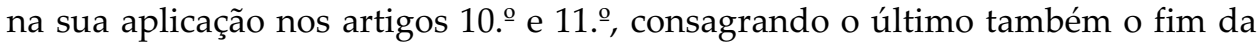
transmissão da responsabilidade criminal, impossibilitando que esta vá para além do agente do crime. A consagração dos princípios da legalidade e personalidade das penas evidenciam a influência dos princípios que potenciaram a reforma das instituições penais em toda a Europa.

Na Câmara dos Deputados, o triénio vintista é marcado por um forte debate constitucional e a necessidade da criação de uma comissão para elaborar um primeiro código penal: “Todos nos queixamos do nosso código penal. Ele é com efeito imperfeitíssimo. Pune com as penas mais horrorosas, e sanguinárias os criminosos, a quem se imputavam crimes, que não existiam. [...] Tem o nosso livro 5. ${ }^{\circ}$ da ordenação pena de morte, para delitos, a que de forma alguma se devia aplicar...". ${ }^{1}$ O ímpeto reformista inicial acabou por se esvanecer com os conflitos sociais e políticos da primeira metade de Oitocentos, embora a década de 1830 seja relevante em matérias de criminalidade e segurança, com o surgimento de novos corpos policiais, em particular as Guardas Municipais de Lisboa e do Porto, ainda que a instabilidade política não potenciasse as transformações necessárias, em particular ao nível da profissionalização dos corpos policiais (Gonçalves, 2014: 27).

A pena de morte constava, portanto, da lei, mas não fora aplicada entre a guerra civil e 1837, tendo, no entanto, voltado nesse mesmo ano. Segundo o Relatório da Comissão do Código Penal de 1861, entre 1837 e 1846 foram executados cerca de três dezenas de indivíduos (Cruz, 1981: 138-140). Nesta fase, existiu um movimento de escritores que se manifestou a favor da abolição da pena de morte. Uma das vozes mais críticas foi a de Alexandre Herculano que, em 1838, escrevia: “Felizmente o progresso intelectual e moral não para; a última preocupação das épocas de barbaridade passará; a palavra algoz chegará a ser um arcaísmo; e os cadafalsos 
apodrecidos e roídos de vermes, serão algum dia, um monumento dos delírios e erros do passado." (Herculano, 1838: 11).

Após 1851 desejava-se a criação de um clima de paz e acalmia interna. Havia necessidade de reconciliação com o passado e uma consciência histórica da violência que existira na sociedade portuguesa. À semelhança do que se passou com a afirmação dos direitos humanos após a II Guerra Mundial, a memória coletiva da violência do passado recente pode ter contribuído para a abolição da pena de morte para crimes políticos. Foi a 23 de janeiro de 1852, que o governo apresentou a proposta que abolia a pena de morte para crimes políticos sem, todavia, nada acrescentar em relação à pena de morte para crimes civis. Durante a discussão, o deputado Mendes Leite submeteu à apreciação um aditamento à proposta do governo, que foi uma medida de alargado consenso. Nos debates de 10 e 29 de março, houve apenas duas vozes que emergiram contra a proposta, pois apesar de concordantes com a abolição da pena de morte para crimes políticos, discordavam da oportunidade naquele momento. O ministro dos Negócios Eclesiásticos e da Justiça, António Luís de Seabra, defendeu que a abolição deveria estender-se aos crimes civis, mas tal não era ainda oportuno tratar. Assim, o Código Penal de 1852 mante-

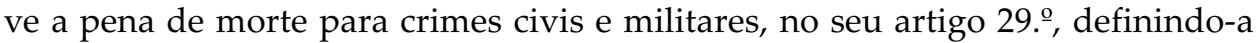
como a simples privação da vida, no artigo 32. ${ }^{\circ}$.

A 6 de junho de 1853, o governo nomeou uma comissão para proceder à revisão do Código Penal recentemente aprovado. O projeto, da autoria de Levy Maria Jordão (1861), foi apresentado às Cortes, enquanto proposta de lei do governo, a 17 de janeiro de 1862. Todavia, o novo código penal, no qual constaria a abolição da pena de morte para crimes civis demorava a ser convertido em lei. Ayres de Gouveia reintroduziu o debate sobre a pena de morte aquando da discussão do orçamento do Ministério dos Negócios Eclesiásticos e da Justiça, a 3 de julho de 1863. Na sua intervenção defendia a abolição da pena de morte para todos os crimes, incluindo os militares, poupando o estado as verbas despendidas com o carrasco. O então ministro dos Negócios Eclesiásticos e da Justiça, Gaspar Pereira, concordou com as propostas e remeteu para as comissões o parecer. Mas a aprovação tardaria em acontecer (Cruz, 1981: 143-167): “Vou mandar para a mesa uma proposta singela [...], é de utilidade geral, porque é relativa a cadeias. No ano passado, quando se discutiu o orçamento, apresentei a propósito de um funcionário público, o carrasco, um projeto para a abolição da pena de morte. A câmara comum alvoroço e impulso de humanidade, digno de melhor resultado, apoiou imediatamente este projeto; foi à comissão que elaborou o seu parecer de pronto, mas quando veio para se discutir responderam por parte do governo - é tarde." ${ }^{2}$

No discurso da Coroa, a 2 de janeiro de 1864, o rei anunciou que seriam submetidas à apreciação do poder legislativo as propostas para a abolição e substituição da pena de morte. Gaspar Pereira apresentou à Câmara a proposta em que, pela inviolabilidade da vida humana e pelo caráter irreparável da pena de morte, se

2 António Ayres de Gouveia, "Diário da Câmara dos Senhores Deputados", sessão de 3 de maio de 1864 . 
deveria abolir totalmente a pena capital em Portugal. Porém, o mandato do governo terminaria em 1864, caducando todos os projetos em proposta de lei pendente, existindo ainda discórdia sobre a abolição da pena para crimes militares ${ }^{3}$ (Cruz, 1981: 200-202). O projeto de Reforma das Prisões acabaria por determinar a abolição da pena de morte para crimes civis, substituída pela prisão celular perpétua, estabelecendo o modelo de Filadélfia para o sistema penitenciário. O projeto foi aprovado por larga maioria. Na opinião pública portuguesa parecia certo o triunfo do movimento abolicionista e inevitável a abolição da pena de morte: "Acabemos por uma vez com esta pena odiosa, levantemos o estandarte da civilização, em guerra declarada à pena de morte [...]. Derrube-se o throno do carrasco, fulmine-se com desprezo a idéa de forca [...]" (Costa Jr., 1866: 16).

A data de 1 de julho de 1867 é um marco para o movimento abolicionista português, quando passavam mais de vinte anos desde a última execução em Portugal, realizada por enforcamento, em Lagos, a 22 de abril de 1846 (Cruz, 1981: 136). ${ }^{4}$ A síntese do debate parlamentar sobre a abolição da pena de morte para crimes civis poderá ser efetuada considerando dois tipos de posições, a favor e contra, havendo, ainda, a necessidade de diferenciar dois tipos de argumentos a favor. Um argumento de natureza filosófico-moral associado à ilegitimidade absoluta da aplicação da pena de morte e na proteção absoluta da vida de qualquer indivíduo, defendido por Ayres de Gouveia ou Francisco Gavicho, e um outro tipo de argumentação, assente em premissas utilitaristas, que validava a legitimidade da pena, mas em função da inexistência de suficiente evidência empírica que comprovasse a sua importância na prevenção do crime, assumir-se-ia que a mesma não seria necessária para o bom funcionamento do sistema penal, fazendo parte desta linha de pensamento o ministro Barjona de Freitas ou os membros da Comissão de Legislação Penal. Aqueles que se posicionaram contra a abolição da pena de morte para crimes civis não poderão ser classificados como apoiantes da pena de morte, defendendo somente a sua existência formal na lei como forma de intimidação social e prevenção do crime. Terá sido esta a linha de pensamento dos cinco deputados que se abstiveram ou que votaram contra o projeto. Não obstante, a elite parlamentar portuguesa parece ter reunido consensos alargados para a criação de uma opinião pública favorável à abolição, não existindo nesse debate uma substancial diferenciação político-partidária (Marques, 2005: 107).

A abolição da pena de morte permitiu a renovação das instituições penais e constituiu-se como um marco do progresso jurídico da sociedade portuguesa da segunda metade de Oitocentos. Apesar de existir alguma prevalência de juristas no parlamento português, os níveis médios de deputados com formação jurídica não eram substancialmente maiores em Portugal do que noutros países europeus (Beste Cotta, 2000), não se constituindo a formação da elite parlamentar como um fator distintivo. Ainda assim, é inegável o contributo da Faculdade de Direito de Coimbra e

3 A questão da pena de morte para crimes militares ficaria formalmente esclarecida com a consagração da mesma no Código de Justiça Militar de 1875.

4 No território colonial de Goa, a 5 de maio de 1857, foi ainda executado por enforcamento João Agostinho de Moraes, pelo crime de homicídio premeditado e roubo (Secco, 1880: 492). 
da Academia das Ciências de Lisboa no movimento abolicionista português. A primeira por se encontrar associada a uma corrente criminalista regida por valores humanitaristas, de onde se desatacam Ayres de Gouveia ou o ministro Barjona de Freitas. À segunda pertenceram Pascoal José de Mello, António Ribeiro dos Santos, Francisco Freire de Mello, Silva Ferrão e Levy Maria Jordão, entre outros, todos eles produtores de doutrina que alimentou o movimento abolicionista português até 1867 (Cruz, 1967: 147).

\section{Conclusão}

A abolição formal da pena de morte para crimes civis em Portugal inseriu-se, assim, numa primeira vaga do movimento abolicionista, iniciada a partir do final da década de 1840, com vários estados a deixarem de aplicar a pena de morte e, em alguns casos, a retirarem-na dos seus ordenamentos penais. A abolição portuguesa aconteceu num contexto distinto da maioria dos países europeus, onde a democracia e a afirmação dos direitos humanos determinaram a abolição da pena de morte no contexto após a II Guerra Mundial. A mudança institucional deveu-se à permeabilidade da opinião pública portuguesa pelas ideias transnacionais liberais e humanistas. O alargado consenso conseguido na opinião pública não poderá ser dissociado da existência de um período de acalmia interna e externa. Em simultâneo, assistia-se à consolidação do liberalismo em Portugal, sendo evidentes o desejo de progresso e de reconciliação com um passado turbulento e violento. Num contexto em que o progresso socioeconómico era reduzido, em função da crescente periferização socioeconómica do país, o progresso possível era o civilizacional ou moral. A abolição da pena de morte foi um exercício de projeção de poder e uma manifestação da vitalidade do estado português para o exterior, num período de perda de poder militar e económico na esfera internacional.

A abolição de facto da pena de morte para crimes civis desde 1846 e formal para crimes políticos desde 1852 foram precedentes relevantes para o desfecho de 1867. Assim, esta transformação institucional parece resultar de uma articulação entre a influência das novas ideias liberais com os interesses nacionais próprios provenientes da afirmação do estado liberal. A aplicação deste modelo de análise integrado possibilitou relevar não só a importância do ideário liberal humanista, mas também dos interesses dos atores e do contexto socioeconómico do país. O mapeamento de processo do movimento abolicionista através da narrativa histórica permite concluir que a Revolução Liberal de 1820 é o marco histórico que origina a intensificação do movimento abolicionista, sendo a Regeneração a conjuntura crítica que viabilizaria a abolição da pena de morte.

\section{Referências bibliográficas}

Anckar, Carsten (2004), Determinants of the Death Penalty. A Comparative Study of the World, Londres, Routledge. 
Beccaria, Cesare (1998 [1764]), Dos Delitos e das Penas, Lisboa, FCG.

Best, Heinrich, e Maurizio Cotta (orgs.) (2000), Parliamentary Representatives in Europe 1848-2000. Legislative Recruitment and Careers in Eleven European Countries, Oxford, Oxford University Press.

Bobbio, Norberto (2004 [1992]), A Era dos Direitos, Rio de Janeiro, Elsevier.

Bozóki, András, e Dániel Hegedus (2018), “An externally constrained hybrid regime: Hungary in the European Union”, Democratization, 25 (7), pp. 1173-1189.

Broadberry, Stephen, e Alexander Klein (2012), “Aggregate and per capita GDP in Europe, 1870-2000: continental, regional and national data with changing boundaries", Journal Scandinavian Economic History Review, 60 (1), pp. 79-107.

Bujon, Pierre (1886), La Peine de Mort devant l'Histoire et devant la Science, Issodun, Eugène Motte.

Caicedo, José Maria Torres (1864), De la Peine de Mort, Paris, E. Dentu.

Carneiro, Maria do Nascimento (1984), “Victor Hugo e a sua correspondência com Portugal", Humanidades: Revista Trimestral da AEFLUP, 4, pp. 45-49.

Cerezales, Diego Palacios (2011), Portugal à Coronhada. Protesto Popular e Ordem Pública nos Séculos XIX e XX, Lisboa, Tinta-da-China.

Churchill, David (2014), "Rethinking the state monopolisation thesis: the historiography of policing and criminal justice in nineteenth-century England", Crime, Histoire et Sociétés/Crime, History and Societies, 18 (1), pp. 131-152.

Cohen, Stanley (1985), Visions of Social Control. Crime, Punishment and Classification, Cambridge, Polity Press.

Collier, Ruth Berins, e David Collier (1991), Shaping the Political Arena. Critical Junctures, the Labor Movement, and Regime Dynamics in Latin America, Princeton, Princeton University Press.

Costa Jr., Paulo José (1866), Discurso contra a Pena de Morte, Lisboa, Typ. Castro Irmão.

Costa, José de Faria (2010), Direito Penal e Globalização. Reflexões Não Locais e Pouco Globais, Coimbra, Coimbra Editora.

Crouzel, Jacques Adrien (1884), La Peine de Mort. Etat de la Question Spécialement en Espagne et en Portugal, Tolouse, Imprimerie et Fonderie Générale du Sud-Ouest.

Cruz, Guilherme Braga da (1967), “Sessão solene em 1 de Julho de 1967, comemorativa do centenário da abolição da pena de morte em Portugal", separata do Boletim da Academia das Ciências de Lisboa, 39, pp. 146-149.

Cruz, Guilherme Braga da (1981), Obras Esparsas, volume II, Coimbra, Coimbra Editora.

Diário da Câmara dos Senhores Deputados da Nação Portugueza, consultável em: http://debates.parlamento.pt/catalogo/mc/cd (última consulta em setembro de 2020).

Ducpétiaux, Edouard (1827), De la Peine de Mort, Bruxelas, H. Tarlier Libraire Editeur. Elias, Norbert (1990 [1939]), O Processo Civilizador, volume II, Rio de Janeiro, Jorge Zahar. Emsley, Clive (2007), Crime, Police \& Penal Policy. European Experiences, 1750-1940, Oxford, Oxford University Press.

Eyttel, Jules (1868), Rapport au Grand Conseil sur la Peine de Mort, Lausana, J.-L. Borgeaud. Fernandes, Paulo Jorge (2005), “Política económica”, em Pedro Lains e Álvaro Ferreira da Silva (org.), História Económica de Portugal 1700-2000, vol. II, Lisboa, ICS, pp. 393-420. 
Fernandes, Ricardo (1971), A Pena de Morte em Portugal, Lisboa, Ordem dos Advogados Portugueses.

Foucault, Michel (2013 [1975]), Vigiar e Punir. Nascimento da Prisão, Lisboa, Edições 70.

Freire, Pascoal José de Mello (1823), Ensaio do Código Criminal, Lisboa, Typ. Maigrense.

Fuller, Catherine (2000), “Primeiro e mais antigo Constitucional da Europa: Bentham's contact with Portuguese Liberals, 1820-1823", Journal of Bentham Studies, 3, pp. 1-13.

Garland, David (1990), Punishment and Modern Society. A Study in Social Theory, Chicago, The University of Chicago Press.

Garland, David (2001), The Culture of Control. Crime and Social Order in Contemporary Society, Nova Iorque, Oxford University Press.

Garland, David (2010), Peculiar Institution. America's Death Penalty in an Age of Abolition, Nova Iorque, Oxford University Press.

Gonçalves, Gonçalo (2014), "Police reform and the transnational circulation of police models: the Portuguese case in the 1860s", Crime, Histoire \& Sociétés / Crime, History $\mathcal{E}$ Societies, 18 (1), pp. 5-29.

Gouveia, António Ayres de (1860), A Reforma das Cadeias em Portugal, Coimbra, Imprensa da Universidade.

Guizot, François (1838), De la Peine de Mort, Bruxelas, Hauman.

Hegel, Georg Wilhelm Friedrich (2005 [1821]), Philosophy of Right, Nova Iorque, Dover.

Herculano, Alexandre (1838), “Da pena de morte”, em Alexandre Herculano, Opúsculos VIII, Lisboa, Tavares Cardoso \& Irmão, pp. 2-11.

Hespanha, António (1989), “Da 'iustitia' à 'disciplina': textos, poder e política penal no Antigo Regime", em Estudos em Homenagem ao Prof. Eduardo Correia, Coimbra, FDC, pp. 493-578.

Hespanha, António (2012), Cultura Jurídica Europeia, Coimbra, Edições Almedina.

Hodgson, Geoffrey M. (2006), “What are institutions?”, Journal of Economic Issues, XL (1), pp. 1-25.

Hoffding, Harald (1912), "State's authority to punish crime", Journal of Criminal Law and Criminology, 2 (5), pp. 691-703.

Hood, Roger, e Surya Deva (2013), Confronting Capital Punishment in Asia Human Rights, Politics, and Public Opinion, Oxford, Oxford University Press.

Ignatieff, Michael (1981), "State, civil society, and total institutions: a critique of recent social histories of punishment", Crime and Justice, 3, pp. 153-192.

Isabella, Maurizio, e Konstantina Zanou (orgs.) (2015), Mediterranean Diasporas. Politics and Ideas in the Long 19th Century, Londres, Bloomsbury Academic.

Johnson, David T. (2012), "Penal systems”, em Helmut K. Anheir e Mark Juergensmeyer (orgs.), Encylopedia of Global Studies, Londres, Sage, pp. 1310-1314.

Johnson, David T., e Franklin E. Zimring (2009), The Next Frontier: National Development. Political Change, and the Death Penalty in Asia, Nova Iorque, Oxford University Press.

Jordão, Levy Maria (1853), Comentario ao Código Penal Portuguez, Lisboa, Typ. José B. Morando.

Jordão, Levy Maria (1861), Projecto de Código Penal Portuguez, Lisboa, Imprensa Nacional. Justino, David (2016), Fontismo Liberalismo Numa Sociedade Iliberal, Alfragide, D. Quixote. Kant, Immanuel (1998 [1785]), Metaphysics of Morals, Cambridge, Cambridge University Press. 
Karimunda, Aimé Muyoboke (2014), The Death Penalty in Africa. The Path Towards Abolition, Farnham, Ashgate.

Krasner, Stephen D. (1984), "Approaches to the State: alternative conceptions and historical dynamics", Comparative Politics, 16 (2), pp. 223-246.

Lacey, Nicola (2014), “Comparative criminal justice: an institutional approach”, Duke Journal of Comparative E International Law, 24 (3), pp. 501-527.

Lains, Pedro (1995), A Economia Portuguesa no Século XIX. Crescimento Económico e Comércio Externo 1851-1913, Lisboa, INCM.

La Torre, Massimo (2010), Law as Institution, Londres, Springer.

Lucas, Charles (1831), Recueil des débats des assemblées législatives de la France sur la Question de la Peine de Mort, Paris, MV Charles-Béchet Libraire.

Lucas, Charles (1869), "De l'abolition de la peine de mort en Portugal”, Orleães, E. Colas.

Lyon, Andrea (2014), The Death Penalty. What's Keeping It Alive, Lanham, Rowman \& Littlefield.

Mahoney, James (2000), "Path dependence in historical sociology", Theory and Society, 29 (4), pp. 507-548.

Marques, Tiago Pires (2005), Crime e Castigo no Liberalismo em Portugal, Lisboa, Livros Horizonte.

Marques, Tiago Pires (2013), Crime and Fascist State, 1850-1940, Londres, Pickering \& Chatto.

Mill, John Stuart (2001 [1861-1868]), Utilitarianism and the 1868 Speech on Capital Punishment, Indianapolis/Cambridge, Hackett Publishing.

Mittermaier, Carl Joseph (1865), De la Peine de Mort, Paris, Maresco Ainé Libraire-Editeur. Moore, Barrington (2010 [1966]), As Origens Sociais da Ditadura e da Democracia, Lisboa, Edições 70.

North, Douglass C. (1990), Institutions, Institutional Change, and Economic Performance, Cambridge, Cambridge University Press.

Novak, Andrew (2014), The Death Penalty in Africa. Foundations and Future Prospects, Nova Iorque, Palgrave.

Olivecrona, Knut (1893), De la Peine de Mort, Paris, A. Rousseau.

Özbudun, E. (2007), “Democratization reforms in Turkey, 1993-2004”, Turkish Studies, 8 (2), pp. 179-196.

Pedreira, Jorge (1998), “As consequências económicas do império: Portugal 1415-1822", Análise Social, 146-147, pp. 433-461.

Pedroso, Zófimo Consiglieri (1874), Um Brado contra a Pena de Morte, Lisboa, Livraria Internacional.

Pereira, Miriam Halpern (2001), A Formação, Diversidade e Assimetrias. Portugal nos Séculos XIX e XX, Lisboa, Imprensa de Ciências Sociais.

Perrot, Michelle (org.) (1980), L'Impossible Prison. Recherches sur le Systéme Pénitentiaire au XIXe Siécle, Paris, Seuil.

Pierson, Paul (2000), "Increasing returns, path dependence, and the study of politics", American Political Science Review, 94 (2), pp. 251-268.

Reis, Jaime (1993), O Atraso Económico Português 1850-1930, Lisboa, Imprensa Nacional Casa da Moeda.

Romão, Miguel (2015), Prisão e Ciência Penitenciária em Portugal, Coimbra, Editora Almedina. 
Rueschemeyer, Dietrich (2009), Usable Theory. Analytic Tools for Social and Political Research, Princeton, Princeton University Press.

Santos, António Ribeiro dos (1815), “Discurso sobre a pena de morte e reflexões sobre alguns crimes", Jornal de Coimbra, VII (XXXIII), pp. 101-147.

Sarat, Austin, e Christian Boulanger (2005), The Cultural Lives of Capital Punishment. Comparative Perspectives, Stanford, Stanford University Press.

Secco, António Henriques (1880), Memórias do Tempo Passado e Presente para Lição dos Vindouros, Coimbra, Imprensa da Universidade.

Sellon, Valentine (1877), La Peine de Mort au Vingtième Siècle, Paris, Guillaumin et C. Spierenburg, Pieter (2008), The Spectacle of Suffering. Executions and the Evolution of Repression, Cambridge, Cambridge University Press.

Spierenburg, Pieter (2011), “The green, green grass of home: capital punishment and the penal system from a long-term perspective", em Austin Sarat e Jürgen Martschukat (orgs.), Is the Death Penalty Dying? European and American Perspectives, Cambridge, Cambridge University Press, pp. 17-46.

Steinmo, Sven (2008), “Historical institutionalism”, em Donatella Della Porta e Michael Keating (orgs.), Approaches and Methodologies in the Social Sciences. A Pluralist Perspective, Cambridge, Cambridge Univerty Press, pp. 118-138.

Thelen, Kathleen (1999), “Historical institutionalism and comparative politics”, Annual Review of Political Science, 2, pp. 369-404.

Thelen, Kathleen (2003), “How institutions evolve: insights from comparative historical analysis", em James Mahoney e Dietrich Rueschemeyer (orgs.), Comparative Historical Analysis in the Social Science, Cambridge, Cambridge University Press, pp. 208-240.

Vaz, Maria João (1998), Crime e Sociedade. Portugal na Segunda Metade do Século XIX, Oeiras, Celta.

Vaz, Maria João (2003), “Prisões de Lisboa no último quartel do século XIX: elementos para o seu estudo", em António Pedro Dores (org.), Prisões na Europa. Um Debate Que Apenas Começa, Oeiras, Celta, pp. 11-21.

Vaz, Maria João (2014), O Crime em Lisboa 1850-1910, Lisboa, Tinta da China.

Maria João Vaz. Professora no Departamento de História do Iscte - Instituto Universitário de Lisboa, e investigadora no Centro de Investigação e Estudos de Sociologia (CIES-Iscte), Lisboa, Portugal. Email: maria.vaz@iscte-iul.pt

João Estevens. Doutorando em Global Studies e investigador no Instituto Português de Relações Internacionais da Universidade Nova de Lisboa.

E-mail: jestevens@fcsh.unl.pt

Receção: 29 de outubro de 2019 Aprovação: 08 de novembro de 2019 